\title{
RESULTS OF RESEARCHES ON PHOTOGRAMMETRIC CALIBRATION OF THE SONY CYBER-SHOT DSC-RX1RM2 CAMERA
}

\author{
Kadnichansky S.A. ${ }^{1}$, Kurkov M.B. ${ }^{1}$, Kurkov V.M. ${ }^{2}$, Chibunichev A.G. ${ }^{2}$, Trubina L.K. ${ }^{3}$ \\ ${ }^{1}$ Geoscan Group, Russia - kadnichanskii.sergei@yandex.ru, m.kurkov@geoscan.aero \\ ${ }^{2}$ Moscow State University of geodesy and cartography (MIIGAiK), Moscow, Russia -, vkurkov@inbox.ru, agchib@mail.ru \\ ${ }^{3}$ Siberian state university of geosystems and technologies, Russia - kaf.ecolog@ssga.ru
}

\section{Technical Commission II}

KEY WORDS: camera calibration, calibration test field, unmanned aerial vehicle Geosan, targeted ground control point, lens distortion.

\begin{abstract}
:
Results of researches of calibration of the SONY CYBER-SHOT DSC-RX1RM2 camera on the basis of the test field aerial survey are given in article. Researches showed that calibration using aerial survey of a calibration test field provides reliable result with a required accuracy. Recommendations about execution of aerial survey and about creation of an operational test field for photogrammetric calibration of the camera before execution of the specific project are made. When aerial survey is carried out with GNSS determination of coordinates of the perspective centers of aerial photos with RMS of coordinates no more than $0.08 \mathrm{~m}$ it is possible to use the selfcalibration mode for photogrammetric network block adjustment without ground control points. At the same time accuracy of the end result of photogrammetric processing commensurable with an accuracy, achieved with ground control points, is provided.
\end{abstract}

\section{INTRODUCTION}

Now issues of calibration of cameras are rather well studied and developed. There are many different approaches of a solution of a task. Apply to calibration of cameras space and flat test objects, apply polynoms of different degrees to the description of systematic error of coordinates of points of the aerial photo (ElHakim and Faig, 1977), (Ebner, 1976), (Grun, 1978), (Kurkov, 1980), (Ackermann, 1981), (Kilpela, 1981), including the polynoms describing a lens distortion (Brown, 1971), (Brown, 1976) or Fourier series (Tang, 2012a), (Tang, 2012a), (Fritsch, 2015), and carry out a solution of a task on the basis of the collinearity equations or complanarities (Chibunichev, 2004), (Chibunichev, 2005).

It is considered that the best result of camera calibration can be received, using the method based on a single photo resection solution for photos of a spatial test object. Other approach, which yields good results is calibration on the basis of the geodetic test field. Today non-metric cameras are widely applied in different applications using unmanned aerial vehicles for 3D measurements (Chibunichev et al, 2018), (Knyaz and Zheltov, 2018) . Taking into account that non-metric cameras are manufactured of the materials subjectd to deformations as a result of changes of the external environment (pressure, temperature, humidity) and not always soft landings of unmanned aerial vehicles, calibration it is necessary to carry out rather often to check interior orientation parameters of the camera.

It is the best of all to carry out calibration before implementation of each project. For this purpose, it is necessary to develop recommendations about creation of the calibration geodetic test field quickly around alleged aerial survey. Results of researches on calibration and self-calibration of the SONY CYBER-SHOT DSC-RX1RM2 camera on the basis of the calibration geodetic

\footnotetext{
${ }^{*}$ Corresponding author
}

test field and recommendations about creation calibration geodetic test field providing calibration with a necessary accuracy are made are given below.

\section{CAMERA CALIBRATION}

The SONY CYBER-SHOT DSC-RX1RM2 camera is a component of the hardware-software complex for aerial mapping intended for obtaining orthophoto, digital terrain models and other spatial data and consisting of the following principal components:

- unmanned aerial vehicle Geosan 101,

- digital Sony CyberShot DSC-RX1RM2 camera,

- GNSS Topcon OEM B111 receiver,

- Agisoft PhotoScan Professional 1.4.4 software product.

The camera used for aerial mapping should meet certain requirements, including, such as existence of the between lens shutter, or a different way of simultaneous exposure of all array elements and existence of the passport or certificate in which the values of the following parameters received as a result of photogrammetric calibration are specified:

- photogrammetric principal distance of the camera (f);

- coordinates of the principal point (xo, yo) in an aerial camera coordinate system;

- values of coefficients of a degree polynom of a radial distortion and also coefficients of a tangential distortion (in the presence). 
The Sony CyberShot DSC-RX1RM2 camera used as a part of a hardware-software complex has the following main characteristics:

- lens type: ZEISS Vario Sonnar $\mathrm{T} *, 8$ elements in 7 groups (3 aspherical elements, including advanced aspherical elements) with the between lens shutter, fixed;

- matrix type: Full frame CMOS matrix of Exmor R (35.9 x $24.0 \mathrm{~mm})$

- nominal focal distance: $35 \mathrm{~mm}$;

- matrix size: 7952 x 5304;

- pixel size: $0.0045 \mathrm{~mm}$.

Focusing of a lens on infinity is rigidly fixed in addition.

The parameters of photogrammetric calibration received as a result of laboratory calibration at the test facility cannot be used by Agisoft PhotoScan software directly as the parameters of photogrammetric calibration used in the Agisoft PhotoScan software product do not correspond to the standard mathematical BrownConrady distortion model. In this regard the Geoscan company set a research problem of an opportunity and quality of photogrammetric calibration of the camera by aerial photography of the calibration test field and the further photogrammetric processing of the received aerial photos to the department of photogrammetry of Moscow State University of geodesy and cartography (MIIGAIK). Justification of optimum parameters of the calibration test field, requirements to the control points, the parameters of aerial survey and parameters of photogrammetric processing by means of Agisoft PhotoScan was the purpose of such researches, including.

For calibration the geodetic test field MIIGAIK located in the Zaoksky district of Tula region and having the following main characteristics was used:

- area -1 sq.km,

- number of the targeted ground control points -47 ,

- RMS error of determination of coordinates of control points relative to base station - $0.02 \mathrm{~m}$.

- terrain height difference $-70 \mathrm{~m}$.

In Figure 1 the layout of the targeted ground control points is shown.

Preparation of the test field consisted in inspection of the reference frame and targeted ground control points, targeting and measurement of additional control points, georeferencing of the base stations used for geodetic support of aerial survey for the purpose of determination of coordinates of the perspective centers by onboard GNSS the receiver.

The aerial survey of the calibration test field was carried out by specialists of the Geoskan Geoscan company by two rows of mutually perpendicular flight strips in the directions NorthSouth and West East with a AGL of $250 \mathrm{~m}$, forward overlap Px $=80 \%$,

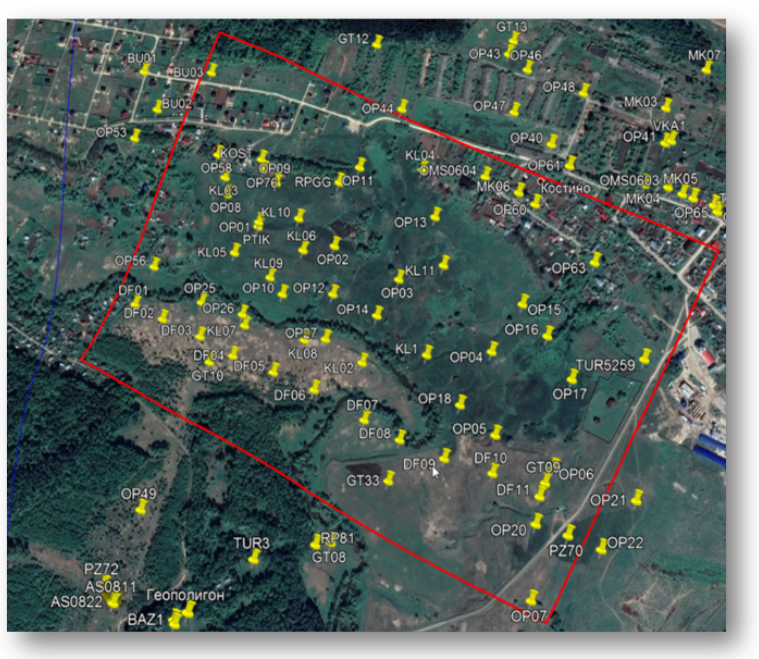

Figure 1. The layout of the targeted ground control points.

side overlap Py $=80 \%$, speed of unmanned aerial vehicle of 72 $\mathrm{km} / \mathrm{h}$. For the specified AGL the GSD of aerial photos is equal $3.3 \mathrm{~cm}$. To the specified AGL corresponds the spatial resolution of aerial photographs equal $3.3 \mathrm{~cm}$.

As a result of the executed aerial survey 717 pictures covering the territory of the calibration test field including 360 pictures of 15 strips for the North-South direction and 357 pictures of 14 strips for the West East direction were taken.

Determination of parameters of calibration was carried out by means of the Agisoft PhotoScan Professional 1.4.4. software having the option of calculation the following parameters of photogrammetric calibration as a result of aerial triangulation combined block adjustment with GNSS coordinates:

- principal distance of the camera $\mathrm{f}$,

- coordinates of the principal point of $x_{0}, y_{0}$,

- coefficients of a radial distortion $K_{1}, K_{2}, K_{3}$,

- coefficients of a tangential distortion $P_{1}, P_{2}$.

The corresponding models of the distortion is described by the following expressions:

$$
\begin{aligned}
x^{\prime} & =x\left(1+K_{1} \cdot r^{2}+K_{2} \cdot r^{4}+K_{3} \cdot r^{6}\right) \\
& +P_{1} \cdot\left(r^{2}+2 x^{2}\right)+2 P_{2} x y, \\
y^{\prime} & =y\left(1+K_{1} \cdot r^{2}+K_{2} \cdot r^{4}+K_{3} \cdot r^{6}\right) \\
& +P_{2} \cdot\left(r^{2}+2 y^{2}\right)+2 P_{1} x y, \\
r & =\sqrt{\left(x^{2}+y^{2}\right)} .
\end{aligned}
$$

$x, y$ - counted from the principal point coordinates of an aerial photo point free from distortion, for example, calculated on spatial coordinates.

Using the maximum opportunities of the available initial materials and data adjustment of network of aerial triangulation with determination of parameters of calibration for all available strips of both directions with use of 45 reference points was executed. The standard deviation of coordinates of the perspective centers of photos was set equal $8 \mathrm{~cm}$. Tie points were chosen automatically, their total number was 1935143 . The RMS residuals on 
control points and - RMS corrections to coordinates of the perspective centers received after block adjustment are given in Table 1 where RMS corrections to coordinates of the perspective centers do not exceed the set standard deviations of their initial values that demonstrates that coordinates of the perspective centers of photos were GNSS-determined with an accuracy characterized RMS errors close to the values given in Table 1. RMS value of the corrections to the measured position of a point on the aerial photo is 1.7 pixels. In Figure 2 the vector field of corrections to positions of tie points in the aerial photo after adjustment characterizing distribution of a residual distortion is shown. The calculated parameters of photogrammetric calibration are given in Table 2 (variant1).

\begin{tabular}{|l|c|c|c|c|c|c|}
\hline & $\mathrm{X}$, & $\mathrm{Y}$, & $\mathrm{H}$, & $\begin{array}{c}\text { In XY } \\
\text { plane, } \\
\mathrm{cm}\end{array}$ & $\begin{array}{c}\text { Total } \\
\mathrm{XYH}, \\
\mathrm{cm}\end{array}$ & $\#$ \\
\hline $\begin{array}{l}\text { RMS } \\
\text { per- } \\
\text { spective } \\
\text { centers }\end{array}$ & 6,0 & 6,0 & 2,4 & 8,6 & 9,0 & 363 \\
\hline $\begin{array}{l}\text { RMS on } \\
\text { control } \\
\text { points }\end{array}$ & 3,6 & 3,5 & 5,6 & 5,0 & 7,5 & 45 \\
\hline
\end{tabular}

Table 1. Results of aerial triangulation block adjustment with use 45 control points.

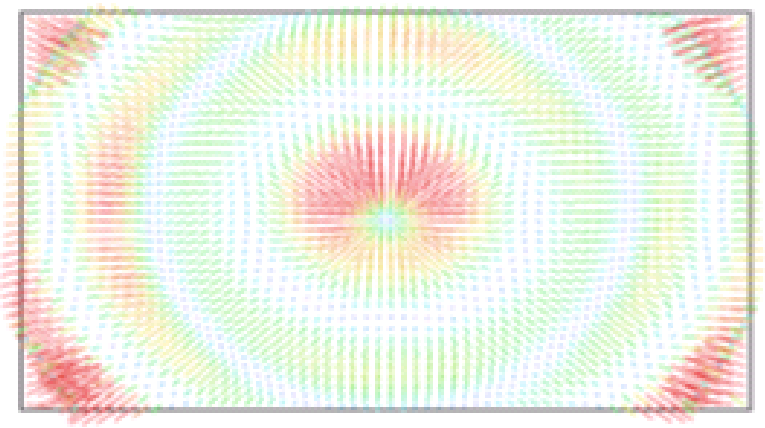

Figure 2. Characteristic picture of the vector field of corrections to positions of tie points on aerial image after adjustment.

In the second and third variants of aerial triangulation block adjustment aerial photos of the different directions of strips were used separately. The calculated values of parameters of calibration are given in Table 2 (variants 2 and 3 ) from where it is visible that results for the different directions of strips significantly (up to 1.3 pixels) differ for yo from the value calculated in the variant 1 . That speaks about unreliability of the decision with one direction of strips in comparison with the decision with two directions.

In the variant 4 the number of control points was reduced up to 15 at their uniform arrangement on the calibration test field, including atrial triangulation block corners. The values of the received parameters presented to Table 2 (variant 4) are very close to values for variant 1 in which 45 control points were used. Reduction of number of control points to five yielded result, considerably different from variants 1 and 4 . In variants 5 and 615 control points were used, but the photogrammetric network was adjusted separately for each of the directions of strips. Received in vari- ant 6 (the direction of strips the North-South) values of some of parameters significantly differ from variants 1 and 4 .

Then an opportunity and quality of adjustment of photogrammetric network with self-calibration without use of control points with accuracy checking by 46 check points was investigated. The received values of parameters of calibration are presented inTable 2 (variants 7 and 8 ). In variant 8 with West-East directions of strips the calculated values of parameters of calibration are close to values of variants 1 and 4 , and RMS errors on check points in both variants slightly differ from RMS residuals on control points for common network adjustment with usage pictures of two directions of strips and 45 control points. This difference is quite explainable by the fact that in this case coordinates of control points were not used in adjustment, i.e. when adjustment the problem of the minimization of residuals on control points which is inevitably affecting result was not solved. Thus, the results of adjustment received in variants 7 and 8 (Table 3 ) allow to make a conclusion on a possibility of use of self-calibration without use of control points when working on aerial mapping in the usual mode.

Some decrease in accuracy of the atrial triangulation executed with aerial photos of flight strips in the North-South direction in comparison with the West-East direction can be explained with the fact that in this area wind in the West-East direction prevails. This side wind (in case of flight strips in the North-South direction) naturally influences the accuracy of determination of coordinates of the perspective centers and at a size of motion blur of the image.

\section{CONCLUSION}

1. Determination of parameters of photogrammetric calibration with use of aerial photos of the calibration test field can be used as the method of photogrammetric calibration providing reliable result with the required accuracy at which interior orientation parameters of aerial photos are defined with error less then physical size of pixel. Necessary conditions for this purpose for SONY CYBER-SHOT DSC-RX1RM2 cameras type are:

- area of the test field not less than 1 sq.km;

- existence of the targeted control points which are evenly distributed on the test field in number of not less than 15 which coordinates are determined relatively reference station with RMS error no more than $0.02 \mathrm{~m}$;

- execution of aerial survey by two rows of mutually perpendicular strips;

- forward overlap of $80 \%$;

- side overlap of 70\%;

- GNSS of determination of coordinates of the centers of photography with RMS error of coordinates not worse than $0.08 \mathrm{~m}$;

2. When executing aerial mapping with GNSS determination of coordinates of the perspective centers of photos with RMS error of coordinates no more then $0.08 \mathrm{~m}$ it is permissible to use the mode of self-calibration without control points in aerial triangulation adjustment. At the same time accuracy of photogrammetric processing of aerial photos commensurable with an accuracy, achieved for adjustment with use of reference points, will be provided.

3. When executing aerial survey it is expedient to consider the direction of wind. Flight strips should be directed downwind and against wind. 


\begin{tabular}{|c|c|c|c|c|c|c|c|c|}
\hline Variant & 1 & 2 & 3 & 4 & 5 & 6 & 7 & 8 \\
\hline Number of CP & 45 & 45 & 45 & 15 & 15 & 15 & 0 & 0 \\
\hline Strips & N-S, W-E & W-E & N-S & N-S, W-E & W-E & N-S & N-S & W-E \\
\hline f & 7539,64 & 7540,11 & 7540,1 & 7539,3 & 7539,8 & 7539,9 & 7540,8 & 7539,2 \\
\hline$x_{0}$ & 20,02 & 20,02 & 19,34 & 20,00 & 19,98 & 19,36 & 19,62 & 20,12 \\
\hline$x_{0}$ & 8,77 & 8,13 & 7,465 & 8,79 & 8,18 & 7,39 & 7,24 & 8,10 \\
\hline$K_{1}$ & $-0,05020$ & $-0,051951$ & $-0,050187$ & $-0,050193$ & $-0,051949$ & $-0,050186$ & $-0,049957$ & $-0,051084$ \\
\hline$K_{2}$ & $-0,169078$ & $-0,162382$ & $-0,17128$ & $-0,169048$ & $-0,162359$ & $-0,171228$ & $-0,172708$ & $-0,167881$ \\
\hline$K_{3}$ & 0,232436 & 0,22298 & 0,238266 & 0,232378 & 0,222995 & 0,238187 & 0,240745 & 0,233215 \\
\hline$P_{1}$ & $-0,000438$ & $-0,000425$ & $-0,000435$ & $-0,000437$ & $-0,000423$ & $-0,000434$ & $-0,000431$ & $-0,000412$ \\
\hline$P_{2}$ & 0,000628 & 0,000656 & 0,000646 & 0,000626 & 0,000655 & 0,000643 & 0,000641 & 0,000649 \\
\hline
\end{tabular}

Table 2. Values of parameters of photogrammetric calibration in pixels.

\begin{tabular}{|c|c|c|c|c|c|c|}
\hline \multicolumn{7}{|c|}{ Direction of strips North-South } \\
\hline & $\begin{array}{l}X \\
\mathrm{~cm}\end{array}$ & $\begin{array}{c}\mathrm{Y}, \\
\mathrm{cm}\end{array}$ & $\begin{array}{l}\mathrm{H}, \\
\mathrm{cm}\end{array}$ & $\begin{array}{l}\text { In XY } \\
\text { plane, } \\
\mathrm{cm}\end{array}$ & $\begin{array}{c}\text { Total } \\
\text { XYH, } \\
\mathrm{cm}\end{array}$ & $\#$ \\
\hline $\begin{array}{l}\text { RMS } \\
\text { per- } \\
\text { spective } \\
\text { centers }\end{array}$ & 6,0 & 6,0 & 2,4 & 8,6 & 9,0 & 363 \\
\hline $\begin{array}{l}\text { RMS on } \\
\text { control } \\
\text { points }\end{array}$ & 3,6 & 3,5 & 5,6 & 5,0 & 7,5 & 45 \\
\hline \multicolumn{7}{|c|}{ Direction of strips East-West } \\
\hline & $\begin{array}{l}\mathrm{X}, \\
\mathrm{cm}\end{array}$ & $\begin{array}{c}\mathrm{Y}, \\
\mathrm{cm}\end{array}$ & $\begin{array}{l}\mathrm{H}, \\
\mathrm{cm}\end{array}$ & $\begin{array}{l}\text { In XY } \\
\text { plane, } \\
\mathrm{cm}\end{array}$ & $\begin{array}{c}\text { Total } \\
\text { XYH, } \\
\mathrm{cm}\end{array}$ & $\#$ \\
\hline $\begin{array}{l}\text { RMS } \\
\text { per- } \\
\text { spective } \\
\text { centers }\end{array}$ & 6,0 & 6,0 & 2,4 & 8,6 & 9,0 & 363 \\
\hline $\begin{array}{l}\text { RMS on } \\
\text { control } \\
\text { points }\end{array}$ & 3,6 & 3,5 & 5,6 & 5,0 & 7,5 & 45 \\
\hline
\end{tabular}

Table 3. Results of check adjustment of photogrammetric network separately in the directions of strips with self-calibration without use of control points.

\section{ACKNOWLEDGEMENTS}

The work was performed with the support by Grant 17-29-04410 of Russian Foundation for Basic Research (RFBR).

\section{REFERENCES}

Agisoft, 2019. Homepage Agisoft, https://www.agisoft.com

Ackermann, F., 1981: Block Adjustment with Additional Parameters. Photogrammetria 36 (6), pp. 217-227.

Brown, D., 1971: Close-range Camera Calibration. Photogrammetric Engineering 37 (8), pp. 855- 866

Brown, D., 1976: The Bundle Method Progress and Prospects. International Archives of Photogrammetry 21 (Part 3), pp. 1-33.
Chibunichev A. G., Ovsyannikov I. V., 2004: Calibration of digital cameras based on images of straight lines. Collection of reports of the International scientific and technical conference dedicated to the 225th anniversary of MIIGAiK. Moscow, pp. 157163.

Chibunichev A. G., Sawicki V.I., Ovsyannikov I.V., 2005: Application of vanishing points for calibration of digital cameras. Izvestiya vuzov "Geodesy and aerophotography", N 4, pp. 97100

Chibunichev, A. G., Knyaz, V. A., Zhuravlev, D. V., and Kurkov, V. M.: PHOTOGRAMMETRY FOR ARCHAEOLOGY: COLLECTING PIECES TOGETHER, Int. Arch. Photogramm. Remote Sens. Spatial Inf. Sci., XLII-2, 235-240, https://doi.org/10.5194/isprs-archives-XLII-2-235-2018, 2018

Dieter Fritsch, 2015: Some Stuttgart Highlights of Photogrammetry and remote Sensing. Photogrammetric Week 15, Ed. D. Fritsch, Wichmann, Berlin/Offenbach, pp. 3-20.

El-Hakim, S.and Faig, W., 1977: Compensation of Systematic Image Errors Using Spherical Harmonics. Proc. American Society of Photogrammetry, Fall Technical Meeting, Little Rock, Arkansas, 18-21 October, pp. 492-499.

Ebner, H., 1976: Self-calibrating Block Adjustment. Bildmessung und Luftbildwesen 44 (4), pp. 128-139.

Grun, A., 1978: Progress in photogrammetric point determination by compensation of systematic errors and detection of gross errors. International Archives of Photogrammetry 22 (Part 3), pp.113-140.

Kilpela, E., 1981: Compensation of systematic errors of image and model coordinates. Photogrammetria 37 (1), pp. 15-44.

Knyaz V. and Zheltov S., 2018. Deep learning object recognition in multi-spectral UAV imagery, Proc. SPIE 10679, Optics, Photonics, and Digital Technologies for Imaging Applications V, 1067920 (24 May 2018); https://doi.org/10.1117/12.2307661

Kurkov V. M., 1980: Methods of systematic image errors compensation. Self-calibration. Izvestiya vuzov "Geodesy and aerophotography", N6, pp. 75-79

Przybilla, H.-J., Gerke, M., Dikhoff, I., and Ghassoun, Y., 2019: INVESTIGATIONS ON THE GEOMETRIC QUALITY OF CAMERAS FOR UAV APPLICATIONS USING THE HIGH 
PRECISION UAV TEST FIELD ZOLLERN COLLIERY, Int. Arch. Photogramm. Remote Sens. Spatial Inf. Sci., XLII-2/W13, pp. $531-538$

Tang, R., Fritsch, D., Cramer, M., Schneider, W., 2012a: A Flexible Mathematical Method for Camera Calibration in Digital Aerial Photogrammetry. Photogrammetric Engineering and Remote Sensing (PERS) 78, pp. 1069-1077

Tang, R., Fritsch, D., Cramer, M., 2012b: New Rigorous and Flexible Fourier Self-Calibration Parameters for Airborne Camera Calibration. ISPRS Journal of Photogrammetry and Remote Sensing 71, pp. 76-85 